\title{
UNDERSTANDING THE NATURE OF SCIENTIFIC ENTERPRISE (NOSE) THROUGH A DISCOURSE WITH ITS HISTORY: THE INFLUENCE OF AN UNDERGRADUATE 'HISTORY OF SCIENCE' COURSE
}

\begin{abstract}
An appropriate understanding of the nature of the scientific enterprise (NOSE) is a key element of scientific literacy and can arguably be influenced through an exploration of the history of science. An elective, undergraduate History of Science course was organized in the form of small-group discussion-based inquiries into the history of science from ancient to modern times. Group discussions focused on STATEMENTS OF CRITICAL SIGNIFICANCE (SOCS) prepared by individual students on assigned readings prior to each class meeting. Small-group discussions were followed by a synthesis, facilitated by the instructor, of points raised in SOCS and other ideas central to the reading. The overarching goal of these activities was to help students see the multifaceted nature of the scientific enterprise in the context of social, political, cultural, and religious milieu of the time period and the geographic setting within which specific scientific activities and developments took place. The impact of this course on student understanding of the NOSE was assessed through the use of VIEWS ON SCIENCE-TECHNOLOGYSOCIETY (VOSTS) instrument administered as pre- and post-test. Qualitative data regarding student understanding of the NOSE were furnished by the final exam on the NOSE written in the form of SOCS at the end of semester. Results based on four semesters of the course offering indicate modest gains in student understanding of specific aspects of the NOSE. They are discussed, along with the usefulness of small-group, discussionbased inquiries into the history of science as a way of enhancing scientific literacy during undergraduate science education.
\end{abstract}

KEY WORDS: history of science, nature of science, scientific literacy, undergraduate science education

\section{INTRODUCTION: UNDERSTANDING OF THE NOSE AS A CRITICAL OutCOME OF SCIENCE EduCATION}

Science (of genetic engineering) has reached what might be the takeoff stage for a new green revolution. But it may instead go the way of nuclear power - a once-promising technology largely rejected by society. (Pollack, 2000)

Pollack strikes at the heart of the importance of people's understanding of science and technology in his statement above. Several recent authors and documents addressing desirable elements of K-16 science education agree that education in the sciences ought to result in more than rote memory of scientific facts and practice of a few scientific processes such as observing, 
measuring, and using the microscope (AAAS, 1994; George, Bragg, de los Santos, Denton, Gerber, Lindquist et al., 1996; Halyard, 1993; National Research Council, 1996; Slaughter, 1993). A key outcome of contemporary science education gleaned from these authors and documents is the development of 'scientific literacy.' While the term 'scientific literacy' is construed differently by different scientists and science educators, a part of its characterization provided by the AAAS (1994) is useful in the context of the present study. According to AAAS (1994, p. xiv), "The lifeenhancing potential of science and technology cannot be realized unless the public in general comes to understand science, mathematics, and technology and to acquire scientific habits of mind." Coming to understand science, according to AAAS (1994), involves understanding the nature of science, which they describe under three components - the scientific world view, scientific methods of inquiry, and the nature of the scientific enterprise. A certain level of understanding of these three components is a "requisite for scientific literacy" (AAAS, 1994, p. 1).

Specific recommendations to help foster appropriate understanding of the nature of science can be found in National Research Council (1996), National Science Teachers Association (1992-1993), and in George et al. (1996). It can, therefore, be argued that current science education reform efforts place a heavy premium on fostering appropriate understanding of the nature of science in K-16 science education. However, one may question why it is so important for anyone to understand the nature of science. There are at least three general responses to this question.

(1) Broad scientific literacy for the general populace. This is important for effective citizenship in a democracy where an increasing number of socio-political issues are science and technology laden. Modern society is faced with numerous choices, issues, and dilemmas resulting from advances in science and technology. In order to make wise choices, resolve issues, and vote intelligently, citizens of modern democracies must be scientifically literate in the sense of understanding the nature of the scientific enterprise. Evidence provided by Driver, Leach, Millar \& Scott (1996) suggests that failure to teach explicitly what constitutes the nature of science leaves most students with simplistic or naïve ideas about science. Such people will lack the knowledge that Osborne, Collins, Ratcliffe, Millar \& Duschl (2003) call "essential" in enabling one to make informed judgments about reports of new scientific discoveries and applications. According to Osborne et al. (2003, p. 694), "in a society where science increasingly permeates the daily discourse, some understanding of its underlying epistemic values, methods, and institutional practices (i.e., the 
NOSE) is essential if the citizen is to engage with the issues confronting contemporary society."

(2) Preparation of scientists who can effectively communicate the nature of their work to non-scientists. More than two decades ago, Gastel (1983, p. ix) wrote, "presenting science to the public is an opportunity to which the scientist should rise. It can help the public, it can enrich our culture, and it can aid science and scientists." In 1993, F. Sherwood Rowland delivered his presidential address to the American Association for the Advancement of Science (AAAS) in which he attributed the most serious problems of scientific progress to "faulty communication" and urged the scientists to sell the importance of science through better communication (Rowland, 1993). Nineteenth century scientists such as Louis Agassiz, Thomas Huxley, and John Tyndall routinely gave popular lectures and wrote directly for the press in an effort to publicize their work. During the early part of twentieth century, however, popularization of science as well as its value as a professional activity by scientists declined (Tobey, 1971). Given the rapidly increasing influence of science on modern society during the latter half of the twentieth century, scientists again started serving an increasingly important role as advisors to policy makers and as communicators of scientific work to non-scientists. Their communication at the present time is more important than ever for influencing appropriate policy decisions, ensuring continued funding and support for scientific research, and attracting more people to scientific careers. Neither of these could be accomplished if scientists fail to help non-scientists understand the nature of their work and the implications of their accomplishments for societal benefit. This implies that scientists must have a sound understanding of the rich complexity of the nature of their work before they can communicate it effectively to others.

(3) Preparation of K-16 teachers who can contribute to (1) and (2) through instruction in the sciences. K-16 science teachers are the key players in accomplishing scientific literacy for the general populace and for preparing scientists who can effectively communicate the nature of their work to non-scientists. During their science education and preparation to become teachers, they should be engaged in learning experiences designed to foster appropriate understanding of various aspects of the nature of science. Research indicates that the teaching practices of science teachers are affected by their beliefs and understanding regarding the nature of science. For example, Gallagher (1991) observed classroom instruction of 25 teachers for over two years and noticed that all teachers placed heavy emphasis on the body of knowledge of science. Interviews with these teachers revealed that their understanding of how knowledge in science is formulated 
or validated was severely limited. In comparing teaching practices relative to beliefs about the nature of science, Brickhouse (1990) discovered the following: teachers who believed in the tentative nature of scientific knowledge (resulting from the possibility of new observations as well as novel interpretations of the same observations) were more likely to encourage students to discuss their observations in the light of scientific theories; on the other hand, teachers who believed that science was an accumulation of knowledge tended to have students follow textbook instructions for conducting experiments and arriving at 'the correct answer.' Thus, teachers understanding of the NOSE plays a significant role in the type of science learning experiences their students will encounter, which, in turn, will influence the students' understanding of the NOSE. Beyond ensuring development of appropriate understanding of the NOSE, science teacher preparation and professional development programs should also engage teachers in instructional design experiences that will enable them to teach in ways that foster the same understanding of the NOSE in their own students. In the absence of appropriate instructional design experiences, teachers' classroom practices may still fall short of promoting appropriate understanding of the NOSE in their students, in spite of their own understanding. As Driver et al. (1996) concluded, portrayal of science in the classroom is influenced by the way teachers are educated.

In addition to the three general reasons for teaching and learning of the NOSE described above, there are other more extensive educational rationales in favor of understanding the NOSE. A prominent, current proponent of such rationales is Michael Matthews. He maintains (Matthews, 1994, p. xv), "The vitality of the scientific tradition, and its positive impact on society, depends upon children being successfully introduced to its achievements, methods, and thought processes, by teachers who understand and value science." This, he argues, can be accomplished by including the history and philosophy of science (HPS) in science instruction and lists ways in which the inclusion of HPS can contribute to the improvement of science teaching and learning. His list is as follows (Matthews, 1994, p. 7):

- HPS can humanize the sciences and connect them to personal, ethical, cultural and political concerns. There is evidence that this makes science and engineering programs more attractive to many students, and particularly girls, who currently reject them.

- HPS, particularly basic logical and analytic exercises - does this conclusion follow from the premises? and, What do you mean by such and such? - can make classrooms more challenging, and enhance reasoning and critical thinking skills. 
- HPS can contribute to the fuller understanding of scientific subject matter - it can help to overcome the "sea of meaninglessness," as Joseph Novak once said, where formulae and equations are recited without knowledge of what they mean or to what they refer.

- HPS can improve teacher education by assisting teachers to develop a richer and more authentic understanding of science and its place in the intellectual and social scheme of things. This has a flow-on effect, as there is much evidence that teachers' epistemology, or views about the nature of science, affect how they teach and the scientific message they convey to students.

- HPS can assist teachers appreciate the learning difficulties of students, it alerts them to the historic difficulties of scientific development and conceptual change. Galileo was forty years of age before he formulated the modern conception of acceleration; despite prolonged thought he never worked out a correct theory for the tides. By historical studies teachers can see what some of the intellectual and conceptual difficulties were in the early periods of scientific disciplines. This knowledge can assist with the organization of the curriculum and the teaching of lessons.

- HPS can contribute to the clearer appraisal of many contemporary educational debates that engage science teachers and curriculum planners. Many of these debates - about constructivist teaching methods, multicultural science education, feminist science, environmental science, inquiry learning, science-technology-society curricula and so forth - make claims and assumptions about the history and epistemology of science, or the nature of human knowledge and its production and validation. Without some grounding in HPS, teachers can be too easily carried along by fashionable ideas which later, sadly, "seemed good at the time."

It is obvious from Matthews' list above that an appropriate understanding of the NOSE through consideration of HPS has extensive educational relevance for all students and teachers. Matthews is not alone in proposing this. He himself recognized and referenced the "long tradition of theoretical writing concerned with establishing the cultural, educational, and scientific benefits of teaching about the nature of science, and of infusing epistemological considerations into science programs and curriculum" (Matthews, 1998, p. 162). This "long tradition" dates back to late nineteenth century and continues to the present time. 


\section{INFLUENCING STUDENT UNDERSTANDING OF THE NOSE: AN UndergraduATE History OF SCIENCE COURSE}

Incorporating history in science instruction has proved to be beneficial in improving student understanding of the NOSE. For example, in comparing the effect of two instructional approaches - one including and the other excluding historical components that emphasized how scientific ideas were formed and provided information about the people responsible for formulating those ideas - Yager \& Wick (1966) found that while concept mastery was not significantly different between students in the two groups, the understanding of the NOSE was superior in students who were taught using the historical approach. Several scholars, such as Duschl (1990) and Matthews (1994), have argued in favor of incorporating the history of science in science instruction. Recognizing the importance of the history of science within science education as far back as 1957, Conant developed the Harvard case histories in experimental science. His lead was followed six years later by and Klopfer \& Cooley (1963) who developed a similar book of eight historical cases to be used in secondary school science. More recent studies indicating positive impact of historical elements on understanding of the NOSE include Soloman, Duveen, Scot \& McCarthy (1992), which indicated significant improvement in middle school students' understanding of certain aspects of the NOSE when historical materials were used in science instruction; Dawkins \& Vitale (1999), which indicated improvement in in-service secondary biology teachers' understanding of "key nature of science concepts" through the use of a "historical cases model'; Abd-El-Khalick \& Lederman (2000), which indicated minimal improvement in college students understanding of NOSE in three different courses (all with a historical focus); and Lin \& Chen (2002), which indicated improvement in pre-service secondary chemistry teacher candidates' understanding of several aspects of NOSE.

Considering the significance of improving student understanding of the NOSE and the positive impact of the use of historical information in accomplishing that goal, the author developed and taught (for four consecutive semesters) an undergraduate course in the history of science offered by the department of biological sciences at an urban, commuter university in midwestern USA. The ultimate goal of the course was to foster an understanding of the multifaceted nature of the scientific enterprise by exploring the history of science from the ancient times to mid-20th century. The 'History of Science' was a semester long, upper level (junior/senior/graduate) elective course taken by biology majors, secondary science education majors (pre-service science teachers), master's level biology students, and occasionally a few non-biology majors. It was a 3 credit hour course in- 
volving two class meetings per week, each 90 minutes long. Alioto (1993) was used as a required text in the course.

Alioto describes major episodes in the history of the development of key scientific ideas in a chronological order and sets them in the context of the geographical, social, cultural, religious, and political milieu within which they developed. At the time the course was taught, Alioto's book was the only text available that provided a comprehensive account of the history of science from ancient times (Greek mythology) to mid20th century (the elucidation of the structure of DNA). Since the course was focused on the history of science itself rather than being focused on science concepts whose teaching was to be enriched by occasional use of historical information, a textbook with comprehensive treatment of the history of science was needed. Alioto's book met that need perfectly, hence it was used as the required course text.

\section{Course Context And Research Methodology}

The major goal of the course was to enhance student understanding of NOSE with regard to the following components:

(1) Aspects of the nature of scientific activity and knowledge (constitutive aspects internal to science);

(2) Social contexts of scientific activity;

(3) Societal implications of scientific activity and accomplishments;

(4) Instructional implications of an understanding of (1), (2), and (3) above.

In an attempt to accomplish the major course goal, the course was structured in the following manner. Each class meeting focused on one chapter in the book in chronological order. Prior to the class meeting, students read the chapter and developed 'statements of critical significance' (SOCS). Figure 1 provides a description of three possible types of SOCS students could write. Students used their written SOCS as reference points during class discussions, which occurred in the following two parts.

(1) Small-group discussions during which students discussed key ideas of the chapter based on the SOCS they had written.

(2) Large-group (whole-class) syntheses of key ideas emerging from (1) above.

During small-group discussions, the author spent a certain amount of time with each group and helped with difficulties and questions as they arose. During the whole-class syntheses, moderated by the author, students were invited to share their insights and discuss and debate each others' 
1. STATEMENT REPRESENTING SUBSTANTIVE CONTENT OF THE READING $\left(\mathrm{SOCS}_{\mathrm{A}}\right)$. This type of statement will express one coherent idea (not a collection of ideas), which captures the substantive content (essence or spirit) of the specific chapter. A careful study of the excerpt from "How to Read a Book" (provided with course syllabus) would be useful in learning how to capture the substantive content of a chapter.

2. STATEMENT REGARDING THE NATURE OF SCIENCE BASED UPON THE RELATIONSHIP BETWEEN SUBSTANTIVE CONTENT OF DIFFERENT CHAPTERS $\left(\mathrm{SOCS}_{\mathrm{B}}\right.$ ). Since the overarching goal of the course is to develop an understanding of the nature of science, it is desirable that you make statements regarding the nature of science as it emerges in various chapters. The relationships (comparison, contrast, similarities, etc.) between examples, people, and events presented in different chapters should, therefore, be pursued to make statements regarding the nature of science.

3. STATEMENT REPRESENTING IMPLICATIONS $\left(\mathrm{SOCS}_{\mathrm{C}}\right)$. This type of statement represents action-level thinking on your part once you have begun to understand the nature of science. It is a statement regarding what should be done. The secondary education majors, for example, may want to think about implications of an understanding of the nature of science to science instruction in the classroom. Biology majors may want to think in terms of implications for issues related to the economics and politics of scientific research.

Figure 1. Types of SOCS.

points as well as raise new questions. The author provided his insights and clarification as appropriate during this time, drawing explicit attention to those events and descriptions in the text that addressed any of the four components of NOSE identified above. In other words, the entire class meeting was an interactive session with multidirectional conversations involving all students and the instructor. The SOCS also served as course examinations at specific points in time during the semester.

One week before the end of the semester, a take-home, comprehensive final exam was given, which also involved writing SOCS. Students turned it in on the scheduled day of the final exam. The description of the final exam is provided in Figure 2. Apart from the SOCS and the final exam, students also wrote a historiography essay on a self-chosen, instructor approved, topic related to the history of science. The details of this essay assignment are provided in Figure 3.

The research question associated with the course can be stated thus: to what extent did participation in this course enhance student understanding of the four components of NOSE identified above? In order to address this research question, a combination of quantitative and qualitative approach was used. For quantitative data collection, 'Views on Science-TechnologySociety' (VOSTS) instrument was used as a pre- and post-test. The pre-test was administered on the first day of class each semester, prior to the begin- 


\section{Biol. 325: History of Science}

Final Exam

In the form of four (4) SOCS (Statements Of Critical Significance), each approximately 50 words long, characterize the nature of the scientific enterprise based upon its history explored during this semester.

Appropriate examples and textbook citations should be used to support or illustrate the points you try to make.

SOCS must be typewritten or word-processed with minimum font size 12, preferably on a single sheet of $8.5 \times 11$ inch paper.

Figure 2. The final exam.

1. APPROVAL OF TOPIC. This is meant to ensure that you have started thinking about the topic and that your thinking is focused along lines which can lead to a scholarly product.

2. ESSAY SYNOPSIS. This must be no more than 3 pages long. It must provide a description of the main thesis and a summary of the line of arguments and historical data to be used to support the thesis. A bibliography of the literature sources consulted to develop the synopsis must be included at the end.

3. FULL ESSAY. This should be approximately 10-15 pages long. It must develop and support a thesis regarding aspects of the nature of science through historiography of specific scientific discovery, invention, or event of your choice. A full bibliography of all sources used must be included at the end.

Figure 3. Elements of the historiography essay.

ning of any course instruction. The post-test was administered on the final examination day at the end of semester. For qualitative data collection, the Final Exam SOCS were evaluated for statements that reflect student understanding in the four aspects of NOSE identified above. Thus, the qualitative data used in the study was of a summative nature.

Over a period of four consecutive semesters, 52 students who responded to the VOSTS instrument at both pre- and post-test times were considered data sources for the research study. Of these 52 students, 44 were undergraduate, three post-baccalaureate (secondary biology teaching certification only candidates), and five graduate (Masters degree) students. Of the graduate students all but one were biology majors. Of the undergraduate students, there were 37 biology majors, three secondary science education majors, one elementary education major, and three from other arts and humanities majors. Gender wise, there were 33 females and 19 males among the study data sources. 
Assessment of Student Understanding of NOSE: Data

ANALYSIS

\section{Quantitative Approach}

\section{The Instrument}

The quantitative approach to assessing student understanding of NOSE involved pre-post administration of selected items from empirically developed 'Views on Science-Technology-Society' (VOSTS) questionnaire (Aikenhead, Ryan \& Fleming, 1989). This questionnaire has been used by several researchers to examine student understanding of science-technology-society interactions (Aikenhead \& Ryan, 1993; Clough, 1994; Rubba, Bradford \& Harkness, 1996). Items on the VOSTS questionnaire lend themselves to assessment of several aspects of NOSE as described in reform documents such as Science for all Americans (AAAS, 1994). According to the developers of this questionnaire, "A teacher can select those VOSTS items that suit his or her particular instruction" (Aikenhead \& Ryan, 1993, p. 32). Items for this study were selected from the VOSTS instrument by the author of the study on the basis of their relationship to course goals as well as their ability to assess those aspects of NOSE that would emerge most clearly from textbook reading and discussion. Selected items were deemed valid and reliable for the purposes of this study on the basis of presentation of the empirical item development procedure and arguments regarding the validity and reliability of the resultant instrument by the developers of the VOSTS questionnaire (Aikenhead, Fleming \& Ryan, 1987). Further treatment of these arguments and procedure can be found in Rubba et al. (1996). Item 1 with all response choices is provided as a sample in Figure 4. The stems of all 20 items used in this study are presented in Figure 5. The classification of VOSTS items into three of the four components of NOSE (identified earlier as focus of investigation in this study) was also done by this author on the basis of the obvious reflection of specific NOSE component in each of the selected item statements.

\section{Scoring Procedure and Data Analysis}

As evident from Figure 4, students pick only one response choice for each item. The scoring of student responses and analysis of resulting data were conducted in accordance with the recommendations made by the developers of the questionnaire and its early users (Aikenhead \& Ryan, 1992; Rubba \& Harkness, 1993). First, the response choices for each item were assigned to one of the following three categories: DESIRABLE (D), ACCEPTABLE (A) and UNDESIRABLE (U). This three category classi- 
Defining science is difficult because science is complex and does many things. But

MAINLY science is:

Your position, basically: (Please read from A to J, and then choose one.)

U/1 A. A study of fields such as biology, chemistry and physics.

U/1 B. A body of knowledge, such as principles, laws and theories, which explain the world around us (matter, energy and life).

D/3 C. Exploring the unknown and discovering new things about our world and universe and how they work.

D/3 D. Carrying out experiments to solve problems of interest about the world around us.

U/1 E. Inventing or designing things (for example, artificial hearts, computers, space vehicles).

A/2 F. Finding and using knowledge to make this world a better place to live in (for example, curing diseases, solving pollution, and improving agriculture).

D/3 G. An organization of people (called scientists) who have ideas and techniques for discovering new knowledge.

$\mathrm{U} / 1 \mathrm{H}$. No one can define science.

U/1 I. I don't understand, or I don't know enough about this subject to make a choice.

U/1 J. None of these choices fits my basic viewpoint.

Figure 4. VOSTS item 1 with response choices and scoring scheme.

fication scheme is similar to that suggested by Aikenhead (Realistic/Has Merit/ Naïve) and reported by Rubba et al. (1996). The three categories used in this study are defined as follows:

- DESIRABLE: The choice expresses a view that is supportable by a wide variety of instances presented in the textbook and their interpretations during class discussions.

- ACCEPTABLE: The choice expresses a view that is supportable by a limited number of instances presented in the textbook and their interpretations during class discussions.

- UNDESIRABLE: The choice expresses a view that is hardly supportable by textbook descriptions and class interpretations.

It must be mentioned here that students in the course were instructed that the instrument was intended to find out what they thought regarding each statement, that it was not a test of their knowledge of the history or nature of science but a measure of their thinking regarding the issues represented in the statements. Thus, the students were not aware of the classification of response choices described above. As such, this method of administering the VOSTS adhered to the intent of the developers of this instrument and measured changes in students' views regarding specifically 
Aspects of the nature of scientific activity and knowledge (constitutive aspects internal to science):

1. Defining science is difficult because science is complex and does many things. But MAINLY science is:

2. Scientific observations made by competent scientists will usually be different if the scientists believe different theories.

3. Many scientific models used in research laboratories (such as the model of heat, the neuron, DNA, or the atom) are copies of reality.

4. When scientists classify something (for example, a plant according to its species, an element according to the periodic table, energy according to its source, or a star according to its size), scientists are classifying nature according to the way nature really is; any other way would simply be wrong.

5. Even when scientific investigations are done correctly, the knowledge that scientists discover from those investigations may change in the future.

6. When scientists investigate, it is said that they follow the scientific method. The scientific method is:

7. The best scientists are those who follow the steps of the scientific method.

8. For this statement, assume that a gold miner "discovers" gold while an artist "invents" a sculpture. Some people think that scientists discover scientific LAWS. Others think that scientists invent them. What do you think?

9. For this statement, assume that a gold miner "discovers" gold while an artist "invents" a sculpture. Some people think that scientists discover scientific HYPOTHESES. Others think that scientists invent them. What do you think?

10. For this statement, assume that a gold miner "discovers" gold while an artist "invents" a sculpture. Some people think that scientists discover scientific THEORIES. Others think that scientists invent them. What do you think?

Social contexts of scientific activity:

11. Community or government agencies should tell scientists what to investigate; otherwise scientists will investigate what is of interest only to them.

12. Politics affects scientists, because scientists are very much a part of society (that is, scientists are not isolated from society).

13. Scientific research would be better off if the research were more closely controlled by corporations (for example, companies in high-technology, communications, pharmaceuticals, forestry, mining, manufacturing).

14. Within the U.S. there are groups of people who feel strongly in favor of or strongly against some research field. Science and technology projects are influenced by these special interest groups (such as environmentalists, religious organizations, and animal rights people).

15. Some communities produce more scientists than other communities. This happens as a result of the upbringing which children receive from their family, schools, and community.

Societal implications of scientific activity:

16. Most U.S. scientists are concerned with the potential effects (both helpful and harmful) that might result from their discoveries.

17. Scientists should be held responsible for the harm that might result from their discoveries.

18. Scientists and engineers should be the ones to decide on future biotechnology in the U.S. (for example, recombinant DNA, gene splicing, developing ore-digging bacteria or snowmaking bacteria, etc.) because scientists and engineers are the people who know the facts best.

19. Scientists should be the ones to decide what techniques will be used with unborn babies in the U.S. (for example, amniocentesis for analyzing chromosomes of the fetus, altering embryo development, test-tube babies, etc.) because scientists are the people who know the facts best.

20. We always have to make trade-offs (compromises) between positive and negative effects of science and technology.

Figure 5. Stems of VOSTS items used, classified by components of NOSE. 
identified components of the NOSE by comparing their pre- and post-test scores.

The definitions identified above were used to determine the classification of response choices into appropriate categories. Since the explicit course goal was to influence student understanding of NOSE, the following response choices were always assigned to the UNDESIRABLE category: "I don't understand"; "I don't know enough about this subject to make a choice"; and "None of these choices fits my basic viewpoint."

Next, the three response categories were scored according to the following numerical values: $\mathrm{D}=3, \mathrm{~A}=2, \mathrm{U}=1$. As an example, the categorization and scoring scheme for response choices in item 1 can be seen in Figure 4. The ordinal data resulting from this categorization of response choices and subsequent numerical scoring lent itself to inferential statistical analysis for examining trends in individual items between assessments over time (pre- and post-tests). The data were subjected to non-parametric analysis using the Sign test. The decision to use a nonparametric statistical procedure was also based on the recommendation made by Rubba et al. (1996). Their recommendation arose from their own test of VOSTS data that they gathered from a similar pre-post administration in college level Science-Technology-Society (STS) and Physics courses.

The Sign test analyzes change, along a specified scale defined by the ordinal data (such as the 3-2-1 scale in this study), by comparing observations within paired data such as those resulting from pre- and post administration separated by a specific treatment. In this test, if the first observation of the pair (score for an item on pre-test) is lower than the second observation (score for the same item on post-test), the result is classified as a positive difference. The result of the reverse condition is classified as a negative difference. Result of no difference between the two observations (identical score on pre- and post-test for an item) is regarded as a tie and is not included in calculating the test statistic. In this study, the null hypothesis, $\mathrm{H}_{0}$ - the difference in VOSTS item response categories (D/A/U) from pre-test to post-test within the treatment population was not asymmetrical (equal number of positive and negative differences) - was tested against the alternate hypothesis, $\mathrm{H}_{1}$ - the difference in VOSTS item response categories $(\mathrm{D} / \mathrm{A} / \mathrm{U})$ from pre-test to post-test within the treatment population was asymmetrical in favor of positive differences (more positive differences than negative differences). In other words, a one-tailed test was used to determine whether or not participation in the History of Science course had positive influence on student understanding of various aspects of NOSE. The null hypothesis was rejected in favor of the alternate 


\section{TABLE I}

Summary of the results of sign test on VOSTS data

\begin{tabular}{rrrrrrrl}
\hline Item & \multirow{2}{*}{ Total $N$} & Negative & Positive & \multicolumn{3}{c}{ Ties } & Test statistic \\
\cline { 5 - 6 } & & differences & differences & $3-3$ & Not 3-3 & Total & result \\
\hline 1 & 52 & 11 & 14 & 9 & 18 & 27 & 0.345 \\
2 & 52 & 6 & 19 & 15 & 12 & 27 & $0.008^{*}$ \\
3 & 52 & 6 & 19 & 8 & 19 & 27 & $0.008^{*}$ \\
4 & 52 & 7 & 15 & 27 & 3 & 30 & 0.067 \\
5 & 52 & 6 & 14 & 6 & 26 & 32 & 0.058 \\
6 & 47 & 6 & 18 & 0 & 23 & 23 & $0.012^{*}$ \\
7 & 51 & 6 & 27 & 5 & 13 & 18 & $0.000^{*}$ \\
8 & 50 & 7 & 21 & 8 & 14 & 22 & $0.007^{*}$ \\
9 & 51 & 9 & 21 & 5 & 16 & 21 & $0.023^{*}$ \\
10 & 48 & 5 & 17 & 1 & 25 & 26 & $0.009^{*}$ \\
11 & 51 & 14 & 13 & 3 & 21 & 24 & 0.500 \\
12 & 52 & 2 & 8 & 41 & 1 & 42 & 0.055 \\
13 & 52 & 10 & 7 & 31 & 4 & 35 & 0.315 \\
14 & 52 & 6 & 17 & 23 & 6 & 29 & $0.018^{*}$ \\
15 & 52 & 10 & 9 & 18 & 15 & 33 & 0.500 \\
16 & 52 & 7 & 13 & 11 & 21 & 32 & 0.132 \\
17 & 52 & 8 & 19 & 18 & 7 & 25 & $0.027^{*}$ \\
18 & 52 & 7 & 15 & 28 & 2 & 30 & 0.067 \\
19 & 52 & 6 & 15 & 25 & 6 & 31 & $0.039^{*}$ \\
20 & 52 & 15 & 15 & 9 & 13 & 22 & 0.500 \\
\hline
\end{tabular}

${ }^{*} p<0.05$.

hypothesis for those items in which positive differences in response categories (D/A/U) from pre-test to post-test turned out to be significant at 0.05 level (significantly more positive differences than negative differences). Over the course of four semesters, a total of 52 students provided pre-post data that was used in this study.

In order to corroborate the results of the Sign test, the VOSTS data were also subjected to McNemar test in a manner similar to that used by Clough (1994) and Rubba et al. (1996). This involved several statistical programming steps to convert the original ordinal data into dichotomous variables required for running McNemar test. In the end, the results of McNemar test turned out to be identical to those of the Sign test. Hence, for the sake of simplicity and brevity, only the results of Sign test are presented here in a summary form in Table I. 
In considering the items that showed significant positive difference, it should be noted that the degree of positive gain for all students was not identical. This is because the Sign test regarded any of the following situations as a positive difference: Moving from a pre-test score of 1 to a post-test score of 3; moving from a pre-test score of 1 to a post-test score of 2; moving from a pre-test score of 2 to a post-test score of 3 . Arguably, however, a student who moved from a pre-test score of 1 to a post-test score of 3 demonstrates a higher degree of positive gain than that attained by the other two situations. It should also be noted that in calculating the test statistic, the Sign test ignores scores that are tied between pre- and post-test. But if the 3-3 ties (a score of 3 on both pre- and post-test) are taken into consideration, one can see how many students were already at the DESIRABLE level for a given VOSTS item at the beginning of the course. Thus, any positive influence of the course in further enhancing their understanding could not be detected through this analysis. This also implies that the lower the number of 3-3 ties for a given VOSTS item, the higher the probability that significant positive differences could result from participation in the course. The numbers of 3-3 as well as non 3-3 ties for each VOSTS item are presented in Table I.

\section{Qualitative Approach}

The qualitative approach involved analysis of the final exam SOCS for evidence of student understanding in each of the following components of NOSE:

(1) Aspects of the nature of scientific activity and knowledge (constitutive aspects internal to science);

(2) Social contexts of scientific activity;

(3) Societal implications of scientific activity and accomplishments;

(4) Instructional implications of an understanding of (1), (2), and (3).

All final exam SOCS were checked for descriptions related to either of the above aspects. The checking involved reading through each SOCS and identifying the ones that directly addressed either of the above stated components of the NOSE. For example, the following SOCS directly addresses the 'instructional implications' component:

Over its history, great scientific advances have come from periods of time in which a significant maelstrom of different ideas and various viewpoints were being proposed, some radically different than what science saw as the accepted view of reality. These ideas often came from a viewpoint outside the current paradigm, which eventually changed how everything was viewed. As future educators and scientists, we should develop a sense for looking at problems and new ideas with an outlook other than our current 'objective' scientific 
viewpoint. Our children should be taught to think this way throughout their education to develop the tools they need to truly 'build a bridge to the 21 st century.'

Such SOCS were deemed relevant for further analysis to identify statements that could be supported by textbook account and class discussion points. Support was determined on the basis of the extent of examples or descriptions from the textbook and points from class discussions used within a SOCS to strengthen the argument. The quantity as well as relevance of class discussion points and textbook accounts to the argument presented in a SOCS determined its degree of supportability. Descriptions that were highly supportable (had several relevant textbook examples and accounts or class discussion points were regarded as strong evidence of student understanding of the specific aspect of NOSE. For example, the following SOCS presents strong evidence of understanding of the "nature of scientific activity,' particularly revolutionary science in this example:

Science does not adhere to the scientific method in most cases of its revolutionary developments. "I frame no hypotheses" was Newton's famous phrase, which he believed gave him the freedom of thought. Einstein did not rely solely on the mechanics, facts, and experimentation of scientific knowledge but rather included a sense of intuition in his scientific studies. Galileo had a reputation for contradicting his professors. Those that dreamt, had feelings or intuitions, and questioned the paradigm in place, aided scientific revolutions.

The quality and, to a limited extent, the number of these statements suggest the degree to which participation in the History of Science course had a positive influence on student understanding of specific components of NOSE.

\section{What Did Students Learn: Discussion of Results}

\section{Aspects of the Nature of Scientific Activity and Knowledge (Constitutive Aspects Internal to Science)}

As the name indicates, this component of NOSE focuses on what is scientific activity all about and what kind of knowledge it generates. It considers the internal features of how scientists go about doing their work and how they come to the conclusions, solutions or answers to their questions. In other words, this component focuses on questions such as the following.

- What, if any, is the scientific method?

- Are scientific observations purely objective or are they influenced by other knowledge (such as that provided by theories)?

- What are the relationships between scientific theories, laws, and hypotheses? 
- To what extent are scientific investigations influenced by the scientists' own imagination and creativity or do these not play any role in the scientist's work?

Items 1-10 in Figure 5 relate to these kinds of questions, thus assessing student understanding of this component of NOSE. It is encouraging to note that in this component, seven of the ten items showed significant positive gain implying that the group as a whole moved in a positive direction from pre-test to post-test test in their understanding of the nature of scientific activity and knowledge.

Items that did not show significant positive gain relate to a broad definition of science (item 1), realist versus instrumentalist notion of classification (item 4) and the tentative nature of scientific knowledge (item 5). It is disturbing to note that after having explored a wide variety of scientific activity in vastly diverse geo-political, socio-cultural, and temporal settings, students still tended to maintain the simplistic (but faulty in the face of the history of science) notions of science, such as the ones represented by response choices A and B for item 1 (see Figure 4). These simplistic definitions can be commonly found in school science textbooks. They are also implicitly promoted in the way most school and college science courses are structured and taught. What is even more disturbing is that even though several students wrote final exam SOCS regarding paradigm shifts and resultant changes in our understanding of the natural world, the group as a whole did not show positive gain in their understanding of the tentative nature of scientific knowledge as assessed by item 5 .

20 of the 52 students (roughly $40 \%$ ) wrote final exam SOCS that made valid statements regarding some aspect of the nature of scientific activity and knowledge. A sampling of these statements is provided in the Appendix. Considering the fact that for most VOSTS items in this component, the pre- and post-test score was a tie (no change) for roughly $50 \%$ of the students (Table I) and that less than 50\% of the students wrote valid SOCS addressing this component on the final exam, it can be said, disappointingly, that the course did not have any spectacular influence on the group as a whole regarding this component of NOSE.

\section{Social Contexts of Scientific Activity}

This component focuses on the relationship between scientific activity and various aspects of the social setting within which it takes place. Geographical locations; political climate, thought and agenda; religious beliefs; cultural practices; and economic conditions were all considered in the textbook as providing a complex social milieu within which scientific activity took place. The goal of class discussions addressing this compo- 
nent of the NOSE was to examine ways in which any of these social factors may have influenced scientific activity and pursuit of scientific knowledge. VOSTS items 11-15 (Figure 5) address some aspects of this component. Student choice of responses for these items indicates the extent to which he/she understood the influence of social factors on scientific activity.

Except for item 14, no significant positive gain was noted for any item in this group. This is interesting because in the final exam SOCS, 17 of the 52 students wrote statements that contained supportable descriptions of the effect of social contexts on scientific activity. Few of these statements are provided as sample in the Appendix. One would suspect that if all of these 17 students developed an appropriate understanding of the social contexts of scientific activity, it would show up as significant positive gains on the VOSTS items. However, that was not the case. One possible explanation is that perhaps these students were not able to translate their understanding into appropriate choices on the VOSTS item due to the nature of the item itself. Another possible explanation is that some of these students entered the course with an already DESIRABLE level understanding of this component of NOSE, hence their pre-post scores were tied and did not contribute to positive differences in the statistical analysis. As Table I indicates, that is actually the case. Better than one third of the study participants showed a 3-3 tie for each of the items related to this component, except for item 11 . This might also explain the disparity between the amount of significant positive results on VOSTS items and the number of final exam SOCS written on this component of NOSE.

\section{Societal Implications of Scientific Activity and Accomplishments}

This component addresses the issue of how scientific activity, knowledge and accomplishments influence society. It goes without saying that humanity in the present age is immensely affected by science and technology. What was explored in the course was the question about the influence of science on humans throughout its history - to what extent and in what ways did science impact human life and how does that compare to the effect of science on humans at the present time.

VOSTS items 16-20 (Figure 5) address this component of NOSE. Of these, only items 17 and 19 showed significant positive gains in student understanding. Interestingly, items 16-19 relate to the responsibility or role of the scientists with regard to societal impact of science. The fact that there was significant positive difference for item 19 but not for item 18 is perplexing because these two items are extremely closely related. Significant positive difference for item 17 is encouraging because it does clearly demonstrates that students have developed an appropriate understanding of 
the nature of scientists' work and their role in how their accomplishments may or may not be used by the rest of the society.

The final exam SOCS were not very encouraging with regard to this component of NOSE. There were only 7 supportable statements that addressed this component, some of which are provided as sample in the Appendix. Given the extensive treatment of the impact of science on society in the textbook, this extremely low number of SOCS is very disappointing. Considering the VOSTS results and final exam SOCS collectively, it can be reported that the group as a whole did not develop appropriate understanding of this component of NOSE to any significant extent.

\section{Instructional Implications of an Appropriate Understanding of NOSE}

Instructional implications of understanding NOSE are not really a part of NOSE itself. However, they have a critical place in the efforts to develop appropriate understandings of NOSE, thus contributing to scientific literacy. Those who are going to be teachers of science at any level (K-16) must develop appropriate understanding of NOSE themselves and then design science instruction in ways that promote the same understanding in their students. Since the student population in this course included pre-service secondary science teachers, the author considered this to be an important goal of the course. Hence, the implications of NOSE to classroom science instruction were explicitly considered during class discussions.

Incidentally, there were no items on the VOSTS questionnaire that addressed the issue of instructional implications of NOSE. This is not surprising because the VOSTS questionnaire was developed to explore student views rather than the views of teachers. The only data in this study that address the instructional implications of NOSE are the final exam SOCS. There were 9 supportable statements that addressed the instructional implications of NOSE. Some of these are provided as a sample in the Appendix. The low number of SOCS addressing this area is not surprising given that pre-service science teachers were a minority in the course in terms of numbers. What is disappointing, however, is that hardly any of the nonteacher participants in the course gave much thought to this component even though it affects everybody.

\section{INTERPRETATION, IMPLICATIONS, AND LIMITATIONS}

Several researchers have reported results of incorporating different instructional strategies in a variety of courses to influence student understanding of NOSE. The use of historical case studies (Irwin, 2000), scientific 
inquiry activities or science process skills instruction (Riley, 1979), and manipulation of the learning environment (Scharmann, 1990) are but a few examples of the instructional strategies used. However, Abd-El-Khalick \& Lederman (2000) claim that there has not been any empirical examination of the influence of complete courses in the history of science on student understanding of NOSE, until, of course, their own study that examined the influence of three different courses (all with a historical focus) on student understanding of NOSE. Thus, studies like the one presented here are a rare species in science education research related to NOSE.

The results of this study are not too different from those reported by Abd-El-Khalick \& Lederman (2000). Like their investigation, this study also indicates minimal improvement in student understanding of NOSE when the results are regarded as a whole. However, this study has two unique features. First, this study considered a focused history of science course whose explicit goal was to influence student understanding of NOSE whereas the study reported by Abd-El-Khalick \& Lederman (2000) considered three different types of courses with prominent historical dimensions in them (an Evolution course, a Controversy course, and a Survey course). Only the Survey course was an actual history of science course. And, only in the Evolution course was there explicit commitment to influence student understanding of NOSE. Second, the history of science course in this study was a full semester course ( 15 weeks) whereas all three courses in the study reported by Abd-El-Khalick \& Lederman (2000) were only ten week long. Considering these two features, one would expect the results of this study to be more positive and more promising regarding the influence of a focused history of science course. However, that has not turned out to be the case.

Regarding the effectiveness of the use of history of science in improving student understanding of NOSE, both Klopfer (1969) and Russell (1981) have noted that students must be engaged in extensive discussion and treatment of historical material and narrative in order to illuminate specific characteristics of science. Abd-El-Khalick \& Lederman (2000) argue, "aspects of NOS that are deemed important for students to understand need to be given explicit attention" (p. 1060). The course described in this study had all of these features. Students were engaged in extensive discussion of historical events, both in small groups and as a whole class. The instructions for SOCS (Figure 1), the historiography essay (Figure 3) and the final exam (Figure 2) all explicitly asked students to think and write about NOSE. Explicit attention was brought during both small group and whole class discussions to all of the four identified aspects of NOSE. Hence, there must be other factors involved here that influenced the results of the study 
and limited the extent of positive influence of the course on student understanding of NOSE. These can be considered as limitations of the study.

The first limitation could be that none of the 52 participants had any background whatsoever in the history of science. Since most of them were biology majors, they had some familiarity with biological history, such as aspects related to Darwin's work, Mendel's work, etc. However, none of the students had any comprehensive understanding of historical progression of developments in any field of science. In spite of focusing attention on NOSE, most students tended to be hung up on the details of historical events. This is not surprising given the kind of course work and instructional approaches they have experienced for the most part: Details are important because that is what they get tested on. So it was hard for students to 'think outside the box' of details and consider the 'bigger picture' of NOSE painted by these details.

A second limitation could be in the analysis of VOSTS data. The assignment of response choices into one of three categories may be challenged. The assignment was done by the author on the basis of the match between response choices and the pictures painted collectively by text narrative and class discussions. This approach is congruent with the original intent of the VOSTS instrument and is appropriate in relation to the nature and goals of the course. However, it can still be argued that the assignments may be biased and not represent a consensus view regarding student understanding of aspects of NOSE represented by various items on the VOSTS instrument. Others who have used this instrument (such as Rubba et al., 1996) involved a panel of scientists, science educators, and philosophers and/or historians of science to assign response choices into categories. Thus, their assignments represented a consensus view. It should be noted, however, that these researchers used the VOSTS instruments in science content courses in which aspects of NOSE were not being explicitly taught. In these courses, understandings related to NOSE were not directly tied to historical representations of science. Therefore, their assignment of response choices needed to be based on a consensus rather than be related to specific historical representations (as was the case in the present study).

A third limitation may lie in the statistical procedure used to analyze the VOSTS data. The Sign test, as mentioned earlier, looks at only the positive and negative differences and ignores the tied scores between pre- and posttests. But when the 3-3 ties for each VOSTS item are considered, one gets a picture of how many students were already at the DESIRABLE level of understanding of the NOSE aspect represented by that item. This information regarding the 3-3 ties can lead to the following two arguments. 
(1) If there was any enhancement in understanding of a student who had a 3-3 tie, it wouldn't show up through the Sign test, hence not contribute to the statistical significance of positive differences. So certain positive influences of the course may go undetected. The results of the 'Social Contexts of Scientific Activity' component may serve as an example to support this argument. In this component, only one of five VOSTS items showed significant positive difference, while four of the five items showed 3-3 ties that represented $35 \%$ to $79 \%$ of respondents. Thus, any gains made by these respondents remain undetected. The number of SOCS written on this component was second highest of all four components, which is an encouraging result, but since the SOCS were not written in a pre-post manner, even they do not help document gains that may have been made by the students with 3-3 ties.

(2) It could be hypothesized that significant positive differences are directly proportional to the number of 3-3 ties. So that items with lower number of 3-3 ties are more likely to show significant positive difference and vice versa. The results support this hypothesis to a limited extent. Of the 10 items that showed significant positive differences, only two (items 14 and 19) had 3-3 ties for greater than 35\% of respondents. The rest all had less than $35 \%$ of respondents indicating a 3-3 tie. Conversely, among the 10 items that did not show significant positive differences, five items showed 3-3 ties for less than 35\% of respondents, one was at the 35\% mark, and four items showed 3-3 ties for greater than $35 \%$ of respondents. It could be argued, therefore, that had the number of respondents with 3-3 ties been less, the VOSTS results may have shown more items with significant positive differences, hence stronger influence of the course on student understanding of NOSE.

A fourth limitation could be the use of only one text. Accounts of same historical events from multiple sources could influence student understanding more deeply. This is because different styles of writing and ways of presenting information have differing extent of influence on student understanding. The same could be said about the instructional strategies used in the course. Since class meetings involved small and large group discussions and mini-lectures only, the more kinesthetic and visual kind of learners may not have been influenced as much as the verbal and analytical kind of learners.

The results of this study imply, in concurrence with those reported by Abd-El-Khalick \& Lederman (2000) that one course in the history of science, even with an explicit focus on NOSE, is not sufficient for sub- 
stantially influencing student understanding of NOSE. However, on the optimistic side, one such course is certainly better than no such course. While the overall gain in student understanding of NOSE at the end of this course was not spectacular, there were certain distinct gains in specific components of NOSE that should not be ignored. For instance, there were significant positive differences between pre-test and post-test on VOSTS items 8,9 , and 10 . These three items relate to the nature of scientific laws, hypotheses, and theories. Positive differences in understanding of these are a major accomplishment, given that misunderstandings regarding the nature of scientific laws, hypothesis, and theories are quite common among students. Similarly, another common misconception held by students is that science follows a singular scientific method. VOSTS item 6 addressed this misconception and the result showed significant positive difference for this item. Thus, it can be argued that this history of science course, explicitly focused on influencing student understanding of NOSE, caused significant improvements in student understanding of some critical aspects of NOSE.

\section{ACKNOWLEDGMENTS}

(1) I am deeply grateful to Dr. Karen Callahan (Statistics Consultant, Academic Computing Center, Appalachian State University, Boone, NC) for her extensive help in the statistical analyses of VOSTS data.

(2) I sincerely appreciate the constructive critique of the anonymous reviewers of IJSME whose helpful suggestions facilitated significant enhancement of the quality of this report.

\section{APPENDIX: SAMPLE SOCS FROM STUdENTS' FINAL EXAMS}

\section{Statements of Critical Significance Regarding the Nature of Scientific Activity and Knowledge}

Humanity has a compelling need to understand nature, from the sub-atomic to the cosmological, in search of his own origins, meaning, and purpose. Initially this was inseparable from theological/mythological thinking. What we call science is the development of theoretical ideas into formal thought processes (paradigms) blended with the practical application of thought processes into ways that solve problems (technology). All of this is intricately interwoven with the cultural, political, geographical, and sociological experiences of the "scientist."

Major turning points in scientific history are directly attributable to a handful of individuals. Interestingly, they had quite a few traits in common. They were independent thinkers, 
non-conformists, and had an obsessive devotion to science. Newton sought the approval of the "heavenly father" through the "visible creation, the universe" (p. 224). Einstein had an unshakable faith in man's ability to solve the "eternal riddle of nature". The resulting paradigms (of these men) truly reflected the individual's perspective, attitudes, and intellectual brilliance. Hence scientific theories embody very human traits. It is not inaccessible textbook facts, it is a reflection of vital humanity.

Science does not adhere to the scientific method in most cases of its revolutionary developments. "I frame no hypotheses" was Newton's famous phrase, which he believed gave him the freedom of thought. Einstein did not rely solely on the mechanics, facts, and experimentation of scientific knowledge but rather included a sense of intuition in his scientific studies. Galileo had a reputation for contradicting his professors. Those that dreamt, had feelings or intuitions, and questioned the paradigm in place, aided scientific revolutions.

Scientific fact is dependent upon the paradigm, which it is viewed through. It is relative to the paradigm that the individual believes to be true. Ancient science viewed nature through a mythopoetical paradigm in which the individual was connected with the natural events and the events took on concrete human qualities and experiences. In medieval Europe, scientific fact was seen through the eyes of Christianity and its scripture as a way to reach the ultimate goal of all knowledge, which was God. Aristotle based scientific facts on the paradigm that the earth was the center of the universe. Conflicting views have arisen between Relativity and determinism versus Quantum and uncertainty regarding particles of matter themselves. The same scientific fact can be explained differently depending on the paradigm the fact is explained by. Paradigms are like colored glasses individuals look through, which shade and influence scientific fact.

Technology and science have almost become one and the same in today's society. The drive to study nature has shifted from a quest to understand nature to a quest for selfimprovement. Technology is understood in society as a tool to improve life by making aspects of life either easier or more productive. This was seen in the period of the "metallurgical culture" which viewed matter only in terms of manipulation and application. The study of science is predominantly a tool for advancement (improvement?) of life styles and social conditions, which is a combination of technology and science. The search for nature's truth is no longer paramount in the drive to study nature, rather technological advancements based on monetary goals are what drive the study of science.

Mathematics is a key element in science. It seems that throughout this book the "gate" of knowledge is opened or justified with the "key" of mathematics. "Newton was the mathematician that Hooke was not" (p. 237). This sentence later proves since Newton had such a mathematical intellect he was able to understand and compute physics better than most other scientists. All science is "tamed by mathematical probability" which shows its relevance in scientific theory (p. 418).

\section{Statements of Critical Significance Regarding the Social Contexts of Scientific Activity}

Religion played a role in the development of science. Religion's presence in science was like a roller coaster ride through time. Early scientific explanations were "mythical" (Greek 
gods). Then Aristotle made science rational and logical by removing religion. Subsequently, religion came back during the Roman Empire, which resulted in science mixing logic with mysticism. The problem that science faced in early times was that it was trying to explain the Bible. The Church had a huge stake in science because if science proved the Bible inaccurate, the Church would crumble. Hence science could not progress much during Christian times because all their efforts went into trying to reconcile religion and science. Islamic science, on the other hand, progressed much further since their science did not need to match their religion because they believed in Koran, which were simply guidelines to live by. Arabs were free to explore because they were unencumbered by historical aspects of revelation as written in the Christian Bible. Today, there are still the unexplainable aspects of nature and the universe, so there is a place for God. But the Church does not strongly govern over science anymore. So science is once again free to explore.

Science cannot be separated from its cultural surroundings. Social conditions have an effect on the evolution of science. In the 1500s Europe was in political turmoil so in turn many changes had initiated and expanded the opportunity for the explosion of Renaissance Naturalism. A new age of science followed this in Europe and it was based on the fact that the renaissance had encouraged imaginative new ideas and as a result, the fall of Aristotelian ideas occurred and new science was on the forefront. Therefore, it is clearly seen that the elements of a society - whether cultural, political, or otherwise - affect science.

Science is unavoidably influenced greatly by culture. Science develops in the confines of cultures, rather than value-free vacuums. Therefore, science is not always objective facts and theories. The emergence of the polis in ancient Greece allowed blending of ideas and debates to occur about science, which were without empirical evidence and those that could argue their points the best influenced scientific thought. During the Renaissance, understanding nature developed in response to the practical needs of the people in a society as the culture began to allow commerce and the possibility of personal gain. Currently, some cultures, including the American culture, view scientific technology as insuring the strength and survival of nations. The American culture currently views science as the objective truth, rather than a discipline, which should be questioned as any other.

The social setting really dictates science's purpose. For example, science began by trying to understand nature qualitatively (Aristotle?). Then during the Roman Empire, military organizations were developing. Consequently, no original science evolved but the science was applied and practical. The medieval times saw an intellectual revolution because the political scene changed with the Crusades. People began to migrate and discover new things and share their information. Schools were opened and books were written. Consequently, practical applications (labs) were combined with theoretical applications (textbook). The Renaissance was healthy for science but there were no new advances. After experiencing war and plagues, science became mechanistic. With the Industrial Revolution, science had to make better materials in less time. During the 19th century, rebellion was brewing. This resulted in another revolution in the next century. Science sort of "lost its innocence" during the 20th century with the dropping of the atomic bomb. But again, with World War II in progress, science was just trying to help the war effort. Since then, science has been trying to create a Utopia where it simply serves technology's needs. 


\section{Statements of Critical Significance Regarding Societal Implications of Scientific Activity}

A scientific revolution (paradigm shift) is the result of the work of normal science trying to fit the data to the current accepted view (save the phenomena). When the data will no longer fit, a genius is required who will take a different perspective and refit the puzzle pieces (data) into a new unified picture. The process of normal science then continues until a revolution is repeated. From this angle, science should be appreciated as a process that adds depth and assistance to our daily lives rather than a means for attaining the final answers and thereby directing our lives. Society must be constantly reminded of the origins of scientific "facts" and taught to view them with the skills of critical thinking, lest one succumb to the belief that "fact" always equals reality.

We need to be careful of our interpretation of nature. There are dangers in its knowledge. Although what we may think is advantageous at the time, this newly acquired knowledge can lead to destruction in the future. The atomic bomb has already proven this. Presently, cloning humans has the potential to have an enormous impact on human life, both positive and negative. Scientists and government officials (the decision-makers) need to set regulations of human cloning to prevent the destructive behavior that cloning has the potential to do.

Science can be seen as a form of religion. In the ancient years, religion had the answers for everything that happened in the world. The Gods or God caused all happenings and mishappenings, even natural occurrences like rain and thunder. Religion offered them comfort for the unknown. Today science plays that role!! Science comforts people because it offers answers and solutions to the things that we don't understand. However, too much faith in science leaves us unprotected in the case of misuse of scientific applications, just like the misuse of the atomic bomb in Hiroshima.

Technology has come a long way. The advancements in technology made science a bit easier to understand. Earlier there was said to be planets and stars; with the invention of the telescope scientists were actually viewing them and were able to make conclusions about the universe and solar system. However, technology also made science loose its innocence when it helped make a destruction tool to manipulate nature (atomic bombs). We need to be careful with all of the technological advances today; it could really hurt our nation.

People consulted the Gods in the ancient times, then the priests in the medieval times, but now all of us seek the soothsayers of the scientific world. Since science has become our means for validation of reality, it possesses tremendous authority over us. Given atomic power, genetic engineering, and technocracy in general, science certainly does possess the power over life.

\section{Statements of Critical Significance Regarding Instructional Implications of Understanding Nature of the Scientific Enterprise}

Over its history, great scientific advances have come from periods of time in which a significant maelstrom of different ideas and various viewpoints were being proposed, some radically different than what science saw as the accepted view of reality. These ideas often came from a viewpoint outside the current paradigm, which eventually changed how everything was viewed. As future educators and scientists, we should develop a sense for looking 
at problems and new ideas with an outlook other than our current 'objective' scientific viewpoint. Our children should be taught to think this way throughout their education to develop the tools they need to truly 'build a bridge to the 21 st century.'

The generalization of science into a specific scientific method places a limit on the progression of science. When a general routine or pattern of thinking becomes adapted it doesn't allow for imaginative new growth through new thought patterns. The scientific education of today has this very problem in that it is biased and structured in a way to discourage imaginative intellectual growth and encourages a systematic regurgitation of textbook material.

It is important to teach science to students but not in ways that prevent the students from thinking "freely." Science needs to be taught in a way that it allows the student to think and justify laws and theories, not just read boring facts from a textbook. Students need to learn to question scientific authority the way the great scientists of the past did.

As a student of science and a future teacher of it, I believe that the implications of change must be taught. Einstein at a young age doubted his teachers and textbooks. The teaching of science needs reform, a revolution if you will. Where would we be today if the reformers of science had just agreed to the facts given to them? I feel it necessary to teach children facts but, more importantly, the ability to realize that science changes as we learn more. This can be achieved through experimentation, thinking beyond the textbook definitions, and having the realization that progress and change occur together.

\section{REFERENCES}

Abd-El-Khalick, F. \& Lederman, N.G. (2000). The influence of history of science courses on students' views of nature of science. Journal of Research in Science Teaching, 37, 1057-1095

Aikenhead, G.S., Fleming, R.W. \& Ryan, A.G. (1987). High school graduates' beliefs about science-technology-society I: Methods and issues in monitoring student views. Science Education, 71, 145-161.

Aikenhead, G.S. \& Ryan, A.G. (1992). The development of a new instrument: "Views on science-technology-society" (VOSTS). Science Education, 76, 477-491.

Aikenhead, G.S. \& Ryan, A.G. (1993). Evaluation of views of high school graduates on STS topics. In R.E. Yager (Ed.), What research says to the science teacher, Vol. 7 (The science, technology, society movement) (pp. 23-33). Washington, DC: National Science Teachers Association.

Aikenhead, G.S., Ryan, A.G. \& Fleming, R.W. (1989). Views on science-technologysociety. Form CDN.mc.5, Department of Curriculum Studies, College of Education, University of Saskatchewan, Saskatoon, SK, S7N 0W0, Canada.

Alioto, A.M. (1993). A history of Western sience, 2nd edn. Prentice-Hall.

American Association for the Advancement of Science (AAAS) (1994). Science for all Americans. New York: Oxford University Press.

Brickhouse, N. (1990). Teachers' beliefs about the nature of science and their relation to classroom practice. Journal of Teacher Education, 41, 53-62.

Clough, M.P. (1994). A formative evaluation of Biology in the Community (BIOCCOM). Unpublished doctoral disertation, University of Iowa Science Education Centre, Iowa City, IA, USA. 
Conant, J.B. (1957). Harvard case histories in experimental science. Cambridge, MA: Harvard University Press.

Dawkins, K.R. \& Vitale, M.R. (1999). Using historical cases to change teachers' understandings and practices related to the nature of science. Paper presented at the National Association for Research in Science Teaching Annual Conference, March 1999. Boston, MA, USA.

Driver, R., Leach, J., Millar, R. \& Scott, P. (1996). Young people's images of science. Buckingham, UK: Open University Press.

Duschl, R.A. (1990). Restructuring science education: The importance of theories and their development. New York: Teachers College Press.

Gallagher, J.J. (1991). Prospective and practicing secondary school science teachers' knowledge and beliefs about the philosophy of science. Science education, 75, 121-134.

Gastel, B. (1983). Presenting science to the public. Philadelphia, PA: ISI (Institute for Scientific Information) Press.

George, M.D., Bragg, S., de los Santos, A.G. Jr., Denton, D.D., Gerber, P., Lindquist, M.M., Rosser, J.M., Sanchez, D.A. \& Meyers, C. (1996). Shaping the future: New expectations for undergraduate education in science, mathematics, engineering, and technology. Arlington, VA: National Science Foundation.

Halyard, R.A. (1993). Introductory science courses: The SCST position statement. Journal of College Science Teaching, 23, 29-31.

Irwin, A.R. (2000). Historical case studies: Teaching the nature of science in context. Science Education, 84, 5-26.

Klopfer, L.E. (1969). The teaching of science and the history of science. Journal of Research in Science Teaching, 6, 87-95.

Klopfer, L.E. \& Cooley, W.W. (1963). The history of science cases for high schools in the development of student understanding of science and scientists. Journal of Research in Science Teaching, 1, 33-47.

Lin, H. \& Chen, C. (2002). Promoting preservice chemistry teachers' understanding about the nature of science through history. Journal of Research in Science Teaching, 39, $773-$ 792.

Matthews, M.R. (1994). Science teaching: The role of history and philosophy of science. New York: Routledge Press.

Matthews, M.R. (1998). In defense of modest goals when teaching about the nature of science. Journal of Research in Science Teaching, 35, 161-174.

National Research Council (1996). National science education standards. Washington, DC: National Academy Press.

National Science Teachers Association (1992-1993). National Science Teachers Association Handbook. Washington, DC: National Science Teachers Association.

Osborne, J., Collins, S., Ratcliffe, M., Millar, R. \& Duschl, R. (2003). What "Ideas-aboutScience" should be taught in school science? Journal of Research in Science Teaching, 40, 692-720.

Pollack, A. (2000). We can engineer nature. But should we? The New York Times (on the Web), February 6, 2000.

Riley, J.P., II. (1979). The influence of hands-on science process training on preservice teachers' acquisition of process skills and attitude toward science and science teaching. Journal of Research in Science Teaching, 16, 373-384.

Rowland, F.S. (1993). President's lecture: The need for scientific communication with the public. Science, 260, 1571-1576. 
Rubba, P.A., Bradford, C.S. \& Harkness, W.J. (1996). A new scoring procedure for the views on science-technology-society instrument. International Journal of Science Education, 18, 387-400.

Rubba, P.A. \& Harkness, W.J. (1993). Examination of pre-service and in-service secondary science teachers' beliefs about science-technology-society interactions. Science Education, 77, 407-431.

Russell, T.L. (1981). What history of science, how much, and why? Science Education, 65, $51-64$.

Scharmann, L.C. (1990). Enhancing the understanding of the premises of evolutionary theory: The influence of diversified instructional strategy. School Science and Mathematics, 90, 91-100.

Slaughter, J.B. (1993). Science and social consciousness. Journal of College Science Teaching, 22, 204-205.

Soloman, J., Duveen, J., Scot, L. \& McCarthy, S. (1992). Teaching about the nature of science through history: Action research in the classroom. Journal of Research in Science Teaching, 29, 409-421.

Tobey, R. (1971). The American ideology of national science 1919-1930. Pittsburgh, PA: University of Pittsburgh Press.

Yager, R.E. \& Wick, J.W. (1966). Three emphases in teaching biology: A statistical comparison of results. Journal of Research in Science Teaching, 4, 16-20.

Department of Biology,

Appalachian State University,

P.O. Box 32027, 572 Rivers Street,

Boone, NC 28608-2027,

U.S.A.

E-mail:dasspm@appstate.edu 